\title{
A Modest Proposal
}

Alan H. Schoenfeld

This essay is about mathematical sense-making. From kindergarten through college, precious little of it is found in our mathematics classrooms. Weby which I mean the community of professional mathematicians and society at large-would all benefit from dramatic change.

I begin with some horror stories. These are documented in the literature, and I'm sure Notices readers have their own to match. The stories confirm that we are teaching our students not to think or analyze and that we are in fact encouraging them to forego common sense. At a recent conference, ${ }^{1}$ for example, Lieven Verschaffel reported that upper elementary school students, trained by their years of school experience, ignore

Alan H. Schoenfeld is the Elizabeth and Edward Conner Professor of Education and affiliated professor of mathematics at the University of California, Berkeley. His email address is a1ans@berke1ey.edu.

Author note: I have borrowed my title from Jonathan Swift, whose Modest Proposal (for Preventing the Children of Poor People in Ireland from Being a Burden to Their Parents or Country, and for Making Them Beneficial to the Public), written in 1729, was that the Irish poor should sell their 1-year-old children to the wealthy for use as food. The full text of his proposal can be found at http://art-bin.com/art/omodest.htm1. Were Swift alive today, he might say that he is gratified to observe (given data on attrition rates, demographics, etc.) that mathematicians have taken his advice-we are eating our young. But the title is the only tongue-in-cheek part of this note. I'm dead serious about the rest.

${ }^{1}$ The Future of Mathematics Education in Europe, sponsored by the Acadaemia Europaea, Lisbon, Portugal, December 16-18, 2007.

Members of the Editorial Board for Doceamus are: David Bressoud, Roger Howe, Karen King, William McCallum, and Mark Saul.

DOI: http://dx.doi.org/10.1090/noti795 the "real world" constraints in the following problem:

How many two-foot boards can be cut from two five-foot boards?

Failing to note that one of the resulting "two-foot boards" actually consists of two one-foot pieces, they simply divide 10 (the combined length of the two boards) by two. We might laugh at the silliness here, but the example is hardly unique and it points to more serious issues. For example, Reusser [2] asked ninety-seven first- and second-grade students the following question:

There are 26 sheep and 10 goats on a ship. How old is the captain?

More than 3/4 of the students "solved" the problem, obtaining their answers by combining the integers 26 and 10. Reusser taped students working on the following problem:

There are 125 sheep and 5 dogs in a flock. How old is the shepherd?

A typical "solution" was

$125+5=130$, this is too big ... and

$125-5=120$, this is still too big...while

$125 / 5=25$.

That works.

I think the shepherd is 25 years old.

He also gave 101 fourth and fifth graders the following nonsense problem:

Yesterday 33 boats sailed into port and 54 boats left it. Yesterday at noon there were 40 boats still in the port. How many boats were still in the port yesterday evening?

One hundred of the 101 students produced a numerical answer to the problem, and only five of the students indicated they thought the task statement was in any way unusual or problematic. 
Kilpatrick [1, p. 140] reports similar phenomena: Recently, some [German] children from kindergarten to grade 6 were confronted with "problems" in which no question was posed:

Mr. Lorenz and 3 colleagues started at Bielefeld at $9 \mathrm{AM}$ and drove the $360 \mathrm{~km}$ to Frankfurt, with a rest stop of 30 minutes.

These stories were inserted into a set of ordinary word problems. The higher the grade level, the more likely the children were to attempt a calculation to solve the problems.

Plainly, students are learning to tolerate nonsensical problems as they go through school! (I assume you've heard the ritual chant, "Ours is not to reason why; just invert and multiply!")

This trend needs to be undone, and we have the tools and experience to fix the problem. The above stories contrast dramatically, for example, with my own experiences as a mathematician and, occasionally, as a student. The wonderful thing about mathematics is that it coheres: when you understand a mathematical idea, everything fits in place beautifully. That beauty is a large part of my attraction to mathematics.

An experience I had as an undergraduate crystallized this understanding for me. In a probability course, the professor was about to write the statement of the binomial theorem up on the board. She paused and said,

You can get confused if you try to write the statement of the theorem from memory. But you don't have to memorize it, because the theorem is so easy to derive. Let the statement come at the end.

Consider the product of $n$ terms of the form $(x+y)$. It will, ultimately, be a collection of terms of the form $x^{k} y^{n-k}$, since each term in the product contains either an $x$ or a $y$ from each of the $n(x+y)$ terms. So, how many $x^{k} y^{n-k}$ terms are there? It's the number of ways you can choose $k x$ 's out of the $n(x+y)$ 's, or $\left(\begin{array}{l}n \\ k\end{array}\right)$. Thus, $(x+y)^{n}=$ $\sum_{k=0}^{k=n}\left(\begin{array}{l}n \\ k\end{array}\right) x^{k} y^{n-k}$.

Having derived the result, she wrote the statement of the theorem in its "proper place" at the beginning of the theorem.

That example has stayed with me for more than forty years, because it captures what I believe about the nature of mathematics. Things may, when one first encounters them, seen strange-when you first look at the formula, it's not immediately apparent why $\left(\begin{array}{l}n \\ k\end{array}\right)$ is there at all or why it should be the coefficient of $x^{k} y^{n-k}$. But, ultimately, there is a good reason-and once one sees it, then what may have seemed arbitrary now seems natural and inevitable. That is, all of elementary mathematics really does make sense. The rules for adding fractions, solving equations, or any other topic our students are likely to encounter in school are, once one understands them, natural and inevitable. But if they are not understood as such, then they appear as arbitrary rules to be memorized and applied mechanically. The results of exposure to such mathematics are the stories that started this essay.

From my perspective, then, the first moral imperative of mathematics instruction is that mathematics must be seen, and taught, as an act of sense-making. Students must be led to see that mathematics is not arbitrary but natural and inevitable - and that they can, with the right experiences, come to grips with it in ways that provide powerful tools for thinking. Whether it is in pure mathematics, where one is rewarded with elegance such as that of the binomial theorem, or in applications and modeling, where the real world phenomena that one models can and should be reflected in the symbols used to represent them, mathematics is and should be experienced in ways that cohere naturally.

Here's a case in point. Many years ago, when I first took a position at the University of Rochester, I had the standard "what are you going to teach" conversation with my department chair. He was happy to have me teach my problem-solving course, but he said I'd have to pay for the privilege: since I got to teach a course of my own design and choosing, I'd have to teach another course that he picked. The course he chose was pre-calculus, because it was universally despised-nobody (including TA's!) wanted to teach such a low-level course, to students who'd obviously had problematic mathematical histories.

The following story is typical of how things went during the course. It was time for us to study the arc length formula $s=r \theta$. I asked the students to read the text overnight and to try to do the homework. The next day I asked how many of them had read the text. All the hands went up. I asked how many had understood it. All the hands went down. So, I said, let's look at some examples. Suppose I had a circle of radius 1 . What's the length of the part of the circumference cut off (a.k.a. "subtended") by a central angle of $90^{\circ}$ ? No problem, they said: that's $1 / 4$ of the way around the circle, or $1 / 4$ of $2 \pi$. How about an angle of $180^{\circ}$ ? Easy. $60^{\circ}$ ? No problem: it's $1 / 6$ of the way around. What 
if we measured in radians? Same thing, you're just saying $[(\pi / 3) /(2 \pi)]$ of the way around, instead of $(60 / 360)$ of the way around. What if the angle was $\theta$ radians? Again, no problem: it's $(\theta / 2 \pi)$ of the way around the circle.

So, I said, we can do circles of radius 1 . What if the radius of the circle was 7 ? Once again, what about a right angle? Same thing, they said: it's $1 / 4$ of the circumference, which is $14 \pi$. A subset of the same sequence of examples led to $(\theta / 2 \pi)(14 \pi)$ for a central angle of $\theta$ radians. After that it was a small step to go from radii of 1 and 7 to a radius of $r$ and the formula $s=r \theta$. What had been mystical now made sense. Moreover, my students began to believe that math can (and should) make sense and that they were capable of doing that kind of sense-making. My problem-solving courses are an advanced version of the same principle.

I truly believe that all of the mathematics in the $\mathrm{K}-16$ curriculum - or at least all of the mathematics that should be in the K-16 curriculum! - can be seen as a set of sensible answers to a set of reasonable questions. My immodest proposal is that we revise the entire curriculum so that all students experience it as such, so that they come to see mathematics as a domain that not only makes sense, but as one that they can make sense of. On a more truly modest scale, I propose that we all, each time we teach, stop to think about how and why the mathematics fits together the way it does and how we can help our students to see it that way. We owe our students no less. Approaching instruction this way will make mathematics easier to learn and will make more accessible to students some of the pleasures of the discipline that we find so appealing. Indeed, if we emphasize sense-making, I predict that more students will take to mathematics and that the rest will have a much better appreciation of its power and uses.

\section{References}

[1] J. KILPATRICK, Problem formulating: Where do good problems come from?, Cognitive Science and Mathematics Education, (A. Schoenfeld, ed.), Erlbaum, Hillsdale, NJ, 1987, pp. 123-148.

[2] K. REUSSER, Problem solving beyond the logic of things, Instructional Science 17 (1988), 309-338.

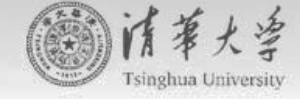

Positions:

Distinguished Professorship; Professorship; Associate

Professorship; Assistant Professorship (tenure-track).

Applications in all areas of mathematics are invited for the above positions. The current annual salary range is between 0.15-1.0 million RMB. Salary will be determined by applicants' qualification. Strong promise/track record in research and teaching are required. Completed applications must be electronically submitted, and must contain curriculum vitae, research statement, teaching statement, selected reprints and/or preprints, three reference letters on academic research and one reference letter on teaching, sent electronically to msc-recruitment@math.tsinghua.edu.cn

Applications are welcome at any time. The review process starts in December 2010, and closes by April 30, 2012. Applicants are encouraged to submit their applications before November 30th.

\section{graduate programs}

PhD programs available in Applied Mathematics, Mathematics, Statistics, and Mathematics Education in the School of Mathematical \& Statistical Sciences; an academic unit of the College of Liberal Arts \& Sciences, Arizona State University Tempe campus. Apply to the PhD program of your choice, teaching assistantships, research assistantships, and fellowship opportunities are available to graduate students.

For additional information:

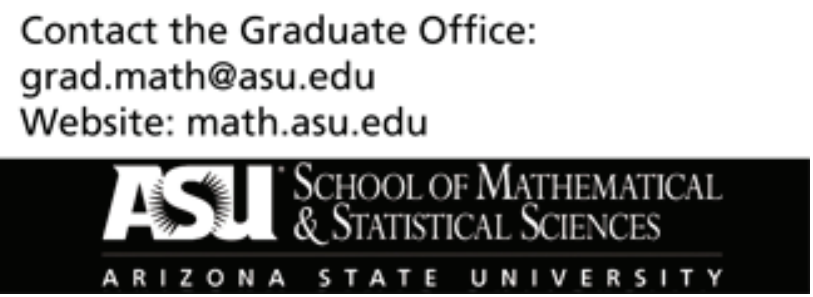

